Securities Trading in the Absense of Dealers:

Trades and Quotes on the Tokyo Stock Exchange

Yasushi Hamao

Joel Hasbrouck

Working Paper No. 90

Working Paper Series

Center on Japanese Economy and Business

Graduate School of Business

Columbia University

November 1994 
Securities Trading in the Absence of Dealers:

Trades and Quotes on the Tokyo Stock Exchange

Yasushi Hamao* and Joel Hasbrouck**

First Draft: August 25, 1992

This Version: October 31, 1994

*Associate Professor of Finance

Graduate School of Business

409 Uris Hall

Columbia University

New York, NY 10027

(212) 854-5631

**Associate Professor of Finance

Suite $9-190$

Stern School of Business

New York University

44 West Fourth St.

New York, NY 10012

(212) $998-0310$

We thank the Tokyo Stock Exchange for providing the data, Hiroshi Nakamura, Masao Takamori and Hidekazu Tominaga of the Exchange for many useful conversations regarding the trading system, and Meng Tan for research assistance. We also thank James Angel, Thomas George, Francis Longstaff, Ananth Madhavan, Mark Ready, Richard Roll, William Sharpe, an anonymous referee, and Chester Spatt (the Editor) for helpful discussions and comments. Previous versions of this paper have been presented at the American Finance Association Meetings in Boston, Columbia-NYU joint workshop, University of California, Los Angeles, Dartmouth College, Hitotsubashi University, Japan Association for Financial Economics, Korea Securities Research Institute, Ohio State University, Stanford University, Seoul National University, State University of New York, Buffalo, University of Tokyo, University of Western Ontario, University of Wisconsin, Madison, and the Western Finance Association Meetings in Whistler. Hamao gratefully acknowledges support from Batterymarch Fellowship and Mitsubishi Trust and Banking Professorship at Columbia University. Part of this research was completed while Hasbrouck was a Visiting Research Economist at the New York Stock Exchange. The comments and opinions contained in this paper are those of the authors only. In particular, the views expressed here do not necessarily reflect those of the directors, members, or officers of the New York Stock Exchange, Inc. 


\title{
Securities Trading in the Absence of Dealers: \\ Trades and Quotes on the Tokyo Stock Exchange
}

\begin{abstract}
This paper investigates the behavior of intraday trades and quotes for individual stocks on the Tokyo Stock Exchange (TSE). The TSE has no designated market makers and is further distinguished by daily and intraday price limits and conversion to limit orders of market order portions that exceed the size of the current quote. We examine the transaction and quote record for three firms for the first three months of 1990. Our findings suggest that the immediacy available (at least for small trades) in the market is high, despite the reliance on public limit orders to supply liquidity. When orders that would otherwise walk through the limit order book are converted into limit orders, execution is delayed, but some orders execute (at least in part) at more favorable prices. Holding order size constant, orders that are delayed in this fashion appear to have a larger information content. Finally, as a consequence of limit order cancellation and autocorrelation in arriving orders, the bid (offer) quote tends to deteriorate further after a sale (purchase).
\end{abstract}


While the initial surge in empirical analyses of market structure centered on U.S. markets in general and the New York Stock Exchange (NYSE) in particular, interest is now shifting toward markets with more diverse structural features. This paper analyzes the behavior of intraday trades and quotes on the Tokyo Stock Exchange (TSE). One of the largest exchanges in the world, the TSE certainly possesses size sufficient to warrant interest. It is also characterized, however, by a number of distinctive institutional features.

Most importantly, the trading mechanism at the TSE does not rely on designated dealers or market-makers. All liquidity is supplied by traders who submit limited price and market orders. Furthermore, by custom and convention, members refrain from placing proprietary limit orders on both sides of the market (although they can represent customers on both sides of the market). This effectively prevents a group of traders that would naturally gravitate toward functioning as de facto dealers from doing so. ${ }^{1}$ In most markets, dealers are responsible for maintaining quotes and liquidity. By examining the TSE, this study seeks to determine the extent to which this function is met by public traders. The central role of the limit order book also characterizes open limit order book systems: the Toronto CATS system and the CAC system used for high-volume stocks on the Paris Bourse. The latter is discussed by Biais, Hillion and Spatt (BHS, 1994).

The TSE is also distinctive in its implementation of market order procedures and price limits. These may cause a delayed adjustment of quotes, effectively closing one or both sides of the market for brief periods, and may also introduce delays for orders which involve price changes. In contrast with the continuity rules of the NYSE, however, there is no requirement that actual trades occur at the intermediate prices to bridge the gap. This study seeks to determine the extent to which the price continuity rules are binding and characterize the delays.

A number of papers have dealt with various aspects of the TSE: Amihud and Mendelson (1989, 1991, 1993), George and Hwang (1994), Hamao (1992), Kato (1990), Lindsey and Schaede (1992), Takagi (1993) and Japan Securities Research Institute (1990). Lehmann and Modest (1994) examine, as does the present paper, the intraday behavior of trades and quotes. Their study provides a detailed cross-sectional view of return and liquidity characteristics based 
on a comprehensive sample of TSE firms. Our paper attempts to achieve a more detailed description of the dynamics of trades and quotes for a few representative firms.

The rest of the paper is organized as follows. Section 1 summarizes trading procedures on the TSE. Section 2 describes the data. The next two sections provide the main results on liquidity. Section 3 discusses preliminary findings on price limits and liquidity. The dynamic properties of trades and quotes are discussed in Section 4. Section 5 presents concluding remarks.

\section{Institutional Details.}

This section summarizes the key institutional features of the Tokyo Stock Exchange (TSE) and is based on the published rules of the Exchange (TSE (1993a, 1993b)) and conversations with Exchange personnel. The TSE is by far the dominant market in the trading of Japanese equities. Among all Japanese firms, the vast majority have their primary listing on the TSE. Although many stocks are cross-listed on regional exchanges (the largest of which is in Osaka), the TSE accounts for most of the trading. In the year of our data sample (1990), $84 \%$ of the share volume in all Japanese equities was conducted on the TSE (TSE (1993c)).

A stock is listed either in the first section, which contains approximately 1200 large and actively traded stocks, or in the second section (approximately 400 smaller, less actively traded stocks.) ${ }^{2}$ All stocks in the second section and most in the first section (including all three stocks in our sample) are "system-traded" with the assistance of a computerized matching system termed (in English) CORES (Computerized Order Routing and Execution System). Procedures for these stocks are substantially, but not entirely, automated. The remaining stocks in the first section (150 actively traded issues) are "floor-traded". Trading in these issues is conducted with a higher degree of human involvement. For both schemes, however, the trading rules are essentially identical: the only difference is whether these rules are implemented with more automation (system-traded) or less (floor-traded). 
All trading takes place under the supervision of a saitori Exchange member. The saitori is neither a broker nor a dealer: he neither represents customer orders nor does he trade for his $\mathrm{c} n \mathrm{n}$ account. The saitori governs the trading process in floor-traded stocks and also (although with lesser involvement) in system-traded stocks. For the latter, the saitori plays an active discretionary role in certain situations described in detail below. Tick sizes are summarized in Table 1. They depend on the stock price and are generally between one-tenth and one percent of the stock price.

The trading day on the TSE is divided into morning (9:00 AM to 11:00 AM) and afternoon sessions (1:00 PM to 3:00 PM in our sample, 12:30 PM to 3:00 PM since April 1991). A trading session on the TSE opens with a call mechanism (itayose), then functions as a continuous double auction (zaraba) until the session closes. In principle, the session may close with a call if there are both buy and sell market-on-close orders, or if the market-on-close orders on one side of the market exceed the (nearest-priced) limit orders on the other side, but this seldom occurs.

The itayose mechanism is straightforward. Buyers and sellers submit market or limited price orders which are cumulated into supply and demand schedules. The intersection determines the equilibrium (see Hamao (1992)). After the itayose clears, the best unexecuted buy and sell orders establish the bid and ask price for the start of the zaraba. Within the zaraba, traders may submit limit orders or market orders. The regular quotes (ippan kehai) disseminated by the Exchange represent the best bid and ask in the limit order book, and most incoming market orders execute by hitting the book. The size of the reported trade is determined by the size of the incoming order. A 1,000 share buy order that executes at one price against limit sell orders of 600 and 400 shares, for example, is reported as a 1,000 share trade.

The principal complication in this framework is the procedure that slows the execution of large market orders. These, for present purposes, are market orders that cannot be fully executed at the current quote, i.e., orders that would otherwise "walk" through the limit order book. When such an order arrives, it partially executes up to the size of the current quote. Then the remaining portion is converted into a limit order at the current quote. This is briefly displayed as an 
indicative quote, an invitation for competing liquidity suppliers to hit the quote. If no such orders arrive, the original order is allowed to proceed to the next price in the book.

Table 2 describes an extended example. For a share price just above $¥ 1,500$, the tick size is $¥ 10$. Suppose that the opening itayose price (or previously executed price in zaraba) is $¥ 1,540$ (time 0 ). The subsequent limit order book is that shown at time 1. The highest bid and lowest offer are displayed as regular quotes. Transaction price limits are most often hit when large incoming orders walk up or down the book. Suppose that a 10,000 share market buy order arrives at time 2 . The first portion of this order, 9,000 shares, is traded immediately at the prevailing offer (time 3).

The remaining 1,000 shares is not, however, immediately executed at the next higher price $(¥ 1,560)$. Instead, the order is represented as a warning bid (kai chui kehai) at $¥ 1,550$. The warning quote is generally issued automatically, but the saitori may instruct the system to suppress this generation. The duration of the warning quote is also at the discretion of the saitori, but for an order in this situation would typically be less than one minute. If this waiting period elapses without the arrival of a sell order priced at the market, $¥ 1,550$ or lower, the remainder of the market order is allowed to hit the $¥ 1,560$ offer on the book (time 4 ).

This process can be repeated at each step of the price, moving one tick at a time. The unexecuted portion of a market order is effectively converted to a limit order, in a fashion similar to that employed in the French CAC system (see BHS). However, unlike the CAC system where a market order in excess of the best quote on the opposite side is converted to a limit order, the market order is eventually permitted to hit the next higher price on the TSE. The handling of a TSE market order therefore lies between that of a CAC market order and a CAC marketable limit order (which is allowed to walk through the book without delay).

Transaction prices on the TSE are also subject to maximum variation limits. Hamao (1992) describes the daily price limits, which are relatively broad. As it happened, none of our stocks hit a daily price limit, despite the high activity and volatility in the sample. Table 1 reports the 
intraday price variation limits. These depend on the stock price and are generally between one and two percent of the stock price (alternatively, between two and ten ticks).

The intraday price limits are often triggered within the day by the arrival of orders of opposite sign. For a stock in the price range of the example the maximum price variation is $¥ 30$ (cf. Table 1). Suppose that a 2,000 share market sell order arrives at time 5 . If this were permitted to hit the bid $(¥ 1,520)$, the resulting change from the previous price $(¥ 1,560)$ would exceed permitted variation ( $¥ 30$ ). A warning quote is also used in this situation, an offer at $¥ 1,550$ (time 6). At this point, an execution can only result from the arrival of a market buy order (which would execute at $¥ 1,550$ ) or a limit buy order priced at $¥ 1,530$ or better (which would execute at the limit price). If neither order arrives, the warning quote may remain at $¥ 1,550$ (possibly for the remainder of the trading session). Alternatively, the saitori may successively revise the warning offer, down to the price consistent with the maximum permitted variation $(¥ 1,530)$. The saitori exercises considerable judgment in this situation as there are no formal Exchange rules governing warning quotes. In the example, the arrival of a buy order priced at $¥ 1,530$ at time 9 triggers an execution (reported at time 10). In the absence of any order arrivals, the warning quote would not be lowered below $¥ 1,530$.

Saitori discretion in the use of warning quotes extends to the exposure duration. A warning quote is sometimes allowed to persist for several minutes. When an incoming market order is progressing through the limit order book, on the other hand, the warning quote is often exposed only momentarily. This does not allow the trader who had entered the exposed limit order a broad opportunity to revise or cancel the order.

The warning quote mechanism effectively imposes on TSE traders a particular strategy. BHS note that when the spread on the Paris Bourse is relatively high; incoming orders are less likely to demand liquidity (seek immediate execution) and are more likely to compete by successively improving on the prevailing quote (and narrowing the spread). The warning quote process mimics this quote improvement process. It removes, however, the trader's discretion in the duration of the quotes and (implicitly) the aggressiveness of the order. Also, although a warning 
quote may stop trading for an indeterminate time, the order underlying the quote is not "stopped" in the sense of the term on the NYSE. A broker stopping an order on the NYSE guarantees execution at a particular price and seeks to improve upon that price. There is no such guarantee on the TSE, as it is conceivable that the opposing quote could deteriorate while the warning quote was pending.

Warning quotes are an informal indication of buying or selling interest. A more formal indication is the "special quote" (tokubetsu kehai). A special quote arises in situations similar to those that trigger a warning quote, but with multiple orders on the active side. In the example, had another seller arrived at time 6 , a special offer quote of $¥ 1,550$ would have been disseminated. Whereas warning quotes are bound by the maximum permitted price variation, a special quote effectively resets the base price. The hypothetical special quote of $¥ 1,550$ at time 6 would be consistent with a subsequent execution price down to $¥ 1,520$ ( $¥ 1,550$ less $¥ 30$ ). The saitori must allow a special quote to persist for at least five minutes (or until it is hit). If it is not hit, the special quote may be revised up to maximum variation ( $¥ 30$ ), i.e., the new special quote is $¥ 1,520$. After five more minutes have passed without the arrival of an opposing order, the quote may be revised again, and so on up to the daily price limit.

When a special quote is posted, the opposing quote is removed from display (actually, posted as zero). In the example, if a special offer quote of $¥ 1,550$ had been posted at time 6 , the $¥ 1,520$ bid would have been removed from the display, and a ' 00 ' null quote (our terminology) would have been shown. It is in this instance impossible for a seller to determine if the $¥ 1,520$ bid has been canceled. In discussing this procedure, TSE personnel note that when an order imbalance of this sort exists, the bid quote tends to be in small size. The TSE therefore views the bid (the size of which is not widely disseminated) as a misleading indicator of the price a seller might receive, and elects not to display it at all. As a formal matter, this removal effectively converts a doublesided open auction to an auction that is sealed-bid on one side. These null quotes are also used when the underlying order is far out of range. 
The gradual and progressive revision of quotes on the TSE is mandated with a view toward smoothing the price transition path and reducing the impact of transient liquidity shock On the NYSE, this purpose is served primarily by price continuity rules, and it is illuminating to compare the two approaches. The contrasting features may be summarized as follows. Suppose that the market is hit by a large public information shock that necessitates a price adjustment. On the TSE, the quotes will exhibit a smooth transition path, but there need not be any transactions along this path. Successive transaction prices may be widely separated. On the NYSE, the specialist (designated market maker) is partially evaluated on the extent to which he maintains transaction price continuity, i.e., limits successive price changes to one tick. In providing this continuity, the specialist may engage in trades that are disadvantageous relative to the current available information. A further distinction between the two exchanges lies in the time needed to complete the transition. On the TSE, adjustment of the quotes may necessitate intervals of waiting at the intermediate price levels. On the NYSE, there are no restrictions on the adjustment speed (in natural time): the transactions establishing the adjustment may be executed within seconds of each other. ${ }^{3}$

Although most transactions result from the interaction of two anonymous orders, the TSE does permit a broker to effect a cross. Rules for large block trading were streamlined in 1967 when off-exchange block trading was prohibited in most circumstances. (There are, however, some rarely-encountered situations in which it is permissible.) Block trades crossed on the Exchange must clear the limit order book and are fully subject to all TSE rules. The regional exchanges (Osaka, in particular) play a role in block trading that is similar to that of the regional exchanges in the U.S. Because there is less trading activity, it is easier for a broker to cross a block away from the primary exchange: spreads are generally wider and there are fewer limit orders to be "cleaned up". Off-TSE block trading is highly seasonal. A March peak arises from a fiscal-year-end trading practice in which a single institutional stockholder may be on both sides of the trade, thereby resetting the value of the holdings (for financial reporting purposes) to current market value. 
The TSE is also distinctive in the level of information permitted to the various classes of participants. Table 3 summarizes market participants and their access to information and order entry facilities. Of particular note is the relatively narrow dissemination given to quotes. Away from the Exchange floor, quote sizes are available only for system-traded stocks and only at the member firm's lead office. Participants without this information cannot know the depth of the market. The practice of converting a partially executed order to a warning quote can be viewed as a way of compensating for this lack of transparency. Off-exchange, warning quotes are available only at lead or branch offices of member firms, and electronic collection or rebroadcast of any data is strictly prohibited.

A member may install in the trading room at his lead office video display terminals that show for system-traded stocks the shape of the order book (prices and quantities, but not identities) both prior to the itayose (opening call) and during the zaraba (continuous trading). These terminals also report the largest cumulative traders (identified by member firm). The number of terminals is limited, and the information is supplied only on demand, in response to a request entered on a keyboard: it is not continuously updated. This information is also available for floor-traded issues, but only by inspection of a screen on the Exchange floor. The information may not be electronically copied or rebroadcast. The only-on-demand feature and the electronic capture prohibition effectively nullify the usefulness of these data as inputs to a real-time automated trading system.

It is especially noteworthy that the information available at the member's lead office includes the total size of the orders underlying a warning or special quote. In principle a trader deciding whether or not to hit a warning or special quote can condition on the total size of the order. While this is a distinct possibility, there are some practical limitations. Since the progression of the warning or special quotes may be rapid and the information is available only on demand, a trader may not always have sufficient time to react. If the response would involve modifying a customer order, additional delay would be introduced by need to confer with the customer. 
For floor-traded issues, customer order are relayed by telephone to a member on the exchange floor. Except for small and pre-opening orders (see Table 3), the member orally communicates the order to the saitori who then enters it in the floor-trading computer system. For system-traded issues, all customer orders must be routed through the member's lead office. The order is entered at a terminal in the member firm's lead office, which electronically transmits the order to CORES.

The links between the TSE and the regional exchanges are not as formalized as those governing the U.S. Intermarket Trading System. Trade reporting is consolidated (as in the U.S.), but there is no consolidated quote reporting. It is the broker's responsibility to survey the quotes and to determine how to route an order. Exchange officials claim that while trade-throughs (execution at a price inferior to another exchange's posted bid or offer) are possible, they rarely occur. For a stock that trades principally on the TSE, the price limit mechanism is applied to TSE trading without formally taking into account transactions occuring at other exchanges. The other exchanges, however, are responsible for ensuring that their trades do not violate the TSE price limits. The roles are reversed for a stock that trades primarily on a regional exchange.

\section{Data and Preliminary Analysis.}

The data sample underlying this study consists of the ordered sequence of transactions and quotes for three securities in the period January 4, 1990 through March 31, 1990, time-stamped to the last minute. The quotes (regular, warning and special) show only prices, not quantities. We do not observe the orders directly, and the data do not contain limit orders away from the best quotes. As noted above, the regular quotes are the best (narrowest) quotes that have not been executed at a given time. Our database essentially reflects the information available at a member firm's branch office (see Table 3), and our analysis will implicitly take this as the relevant public information set. Traders at the member firm's lead office may also have access (by request) to data describing the shape of the limit order book and the identity of the initiators of large executed 
transactions. This roughly corresponds to the information available to a member on the floor of the NYSE.

The data were provided by the Exchange in the form of photostat computer printouts (roughly 5,000 pages), converted into machine-readable form using an optical scanner, checked and edited. The securities, randomly chosen from system-traded issues in the first section, are: Mitsui Construction, Nikon and Japan Airlines (JAL). There were 59 trading days in this period. January 4, 1990 was the first trading day of the year, and the market was open only in the morning. Due to mishaps in the collection of the data, we are missing one day for each stock (February 27 for Nikon and JAL, and March 2 for Mitsui Construction). This leaves 58 morning sessions and 57 afternoon sessions.

Figure 1 depicts the daily closing prices over the observation period. All three stocks in our sample declined in value. (The Tokyo market experienced a downward movement; the closing value of the value-weighted Tokyo Stock Price Index (TOPIX) declined from 2,867.70 on January 4 to 2,227.48 on March 30.) Table 4 reports various summary statistics. At then-current exchange rates, the median transaction sizes roughly correspond to dollar values of $\$ 21,000$ (Mitsui Construction), $\$ 36,000$ (Nikon), and $\$ 26,000$ (JAL). Average spreads are very close to their respective minimum tick size, and are $1 \%$ or less. For each stock, the tick size remained constant over the sample period.

Nikon and Japan Air Lines are also traded on the regional exchanges; Mitsui Construction trades only on the TSE. While we do not possess market share data covering our sample period, we have examined off-TSE trading activity for the first quarter of the following year (1991). The TSE's share of trading volume for the quarter was $82 \%$ for Nikon and $95 \%$ for Japan Air Lines. These stocks further exhibited the seasonal pattern mentioned in Section 1. The monthly shares for January, February and March were $98 \%, 83 \%$ and $76 \%$ for Nikon, and $98 \%, 94 \%$ and $94 \%$ for JAL.

As in the U.S. data, most market statistics exhibit a marked intradaily pattern. ${ }^{4}$ Figures 2,3 and 4 present plots of average squared return, average proportional spread, and average trading 
volume for fifteen-minute intervals throughout the trading day. The mean squared return and spread tend to be elevated at the beginning and end of the trading day. The volume tends to be elevated at the beginning and end of the trading sessions. ${ }^{5}$

\section{The Availability of Immediacy.}

A trader enjoys immediacy in a market when an order can be instantaneously executed. Speed of execution may be important for reasons of hedging, implementation of dynamic trading strategies, minimization of ongoing market monitoring costs, or simply an investor's desire for closure on an allocation decision. When an exchange's procedures require a market maker to post quotes at all times, immediacy is available at some price whenever the market is open. In the absence of such a dealer (as on the TSE), immediacy will be unavailable whenever there is no public limit offer to buy or sell. In addition, the TSE's procedures for handling large market orders and the intraday price limits may also impair immediacy. This section examines the evidence bearing on the availability of immediacy and also the execution delays introduced by the order procedures.

By way of preliminaries, Table 5 summarizes the number and relative durations of times when immediacy is unavailable on one or both sides of the market. A relative duration is the total time that immediacy was impaired as a percentage of the time that the TSE was in principle open over our sample period. The greatest impairment of liquidity is associated with opening delays: the highest relative duration in our sample of firms is $7.5 \%$ (of the total time the Exchange was open). These stem from a relatively small number of instances when the opening delay was on the order of an hour. It is not possible to ascertain when no bid or offer exists in the system. The "null" quote category (a relative duration of at most $1.4 \%$ in our sample) includes this possibility, but null quotes are also posted when the opposing quote is a special bid or offer. Price variation events are those in which a quote is posted, but hitting such a quote would violate the maximum permitted intraday price variation (a relative duration of at most $1.8 \%$ in our sample). Finally, times in which an order is in progress on the same side of the market (as indicated by a warning or 
special quote) account for a relative duration of up to $1.3 \%$ in our sample. Although these relative durations may appear small, they do not take into account the demand for liquidity. The market may be effectively unavailable exactly when the demand for liquidity is high.

While it would obviously be desirable to track the performance of all incoming orders, these are not contained in our data. Partial inference is possible, however, from the transaction and quote record. To this end we define an order sequence as the consecutive sequence of trade and quote events that spans the smallest time for which we can be certain that the order that initiated the sequence has been fully processed. The simplest sequence arises when a normal bid and offer are present, a transaction takes place at either, and then the normal quotes are reaffirmed. This may confidently be presumed to have arisen from an incoming market order. If the order could not have been fully executed at one price, however, the sequence would have involved warning quotes and multiple transactions.

More formally, the start of an order sequence in the buy direction is indicated by a transaction above the current bid quote or a quote that improves on the current bid. Continuation of the order sequence is inferred from warning or special quote conditions. The ending point of an order sequence is fixed by the posting of a regular quote, or by the end of the trading session. First transactions of both morning and afternoon sessions are excluded since they employ a call auction (itayose). Limit orders at or away from the current quote ("passive orders") cannot be discerned in our data. Furthermore, the inferred sequence may actually span multiple incoming orders: if another order arrives on the same side of the market during a warning or special quote sequence, it will not be possible to infer from the reported transactions when the execution of the first order is completed and that of the second order has begun.

In examining the outcomes of orders and order sequences; we are implicitly ignoring the endogeneity of order submission strategies. Traders can and do condition their orders on current market conditions. In principle, for example, a trader with access to the display at a member's lead office can obtain the shape of the limit order book (data we do not possess), and can so forecast the progress of trades and warning quotes that would result from an order of a given size. 
Knowledge that the book is thin may lead the trader to trim the size of the order. This conditioning is ignored in our analysis.

Table 6 describes the order sequences in the sample. The vast majority result from market orders that are completed in a single transaction. Quote improvements constitute a smaller number of instances. It is useful to categorize sequences of longer than one event according to whether the duration of the sequence is longer than one minute (the time resolution of the data). Of the multiple-event sequences that start with a trade, roughly half of these $(253 / 547=46 \%)$ are completed in the same minute. Many of these sequences involve orders that are permitted through the book without interference. ${ }^{6}$ The corresponding figure for multiple-event sequences that started with a quote revision is $131 / 357=37 \%$. All of the multiple-event sequences involved warning or special quotes, with the former being more common. In many of these sequences, a special or warning quote was hit by an incoming opposing order.

A one-event sequence that began with a quote revision reflects a regular bid or offer that improved on the prevailing bid or offer, and it is reasonable to assume that this was the intent of the trader submitting the order. This assumption cannot be made for longer sequences. For example, if the offer quote lies beyond the maximum price variation, a market buy order will appear as a sequence of warning quotes (some of which may be hit by incoming sell orders). A sequence of warning quotes might also arise from a limit order that improves upon the current bid by more than one tick.

Since the warning and special quotes constitute a particularly distinctive feature of the TSE mechanism, it is useful to examine the outcomes of these quotes in greater detail. A warning or special quote can lead to another revised warning or special quote, a regular quote, a null quote (if the order is withdrawn and the next-best order is out of range). The outcome may also be a transaction. The special or warning quote may itself be hit by an opposing order. Alternatively, the order behind the special or warning quote may be allowed to hit the prevailing counterparty quote. Finally, the trading session may close with the quote left hanging. 
Table 7 reports the frequency of occurrence of these outcomes and also the mean durations. The average durations of the warning quotes are brief, under three minutes. These averages include, however, many instances where the warning quote was exposed for under one minute. It is likely that most of the 755 cases where a warning quote was followed by a trade correspond to instances where an order is walking through the book. Nevertheless, $19 \%$ of the warning quotes $(199 / 1,052)$ were hit by incoming orders, with a mean duration of 0.66 minutes. This suggests that these orders may encourage competing providers of liquidity to come forth. The incidence of special quotes is roughly $7 \%(77 / 1,052)$ of that of warning quotes. Since these cannot be revised before five minutes have elapsed, the durations are longer than those of warning quotes. Nevertheless, in $51 \%$ of the occurrences (39/77), the special quote was hit by an incoming order.

Our sample exhibited no instance of a warning quote in which the opposing quote was withdrawn or moved away from the order. The absence of such behavior may reflect the irrelevance of opposing warning quotes in limit order strategy or it may simply arise from the practical difficulties of detecting and reacting to these quotes. The extent of quote revisions in the face of special quotes could not be ascertained because no opposing quotes are displayed.

Taking the volume of an order sequence and the submission time as predetermined, the impact of these variables on the duration of the sequence may be estimated from the regression specification:

$$
\left(\begin{array}{l}
\text { Order Sequence } \\
\text { Duration }
\end{array}\right)_{i}=a\left(\begin{array}{l}
\text { Sequence } \\
\text { Volume }
\end{array}\right)_{i}+b\left(\begin{array}{l}
\text { Log Sequence } \\
\text { Volume }
\end{array}\right)_{i}+\sum_{j=1}^{16} c_{j}\left(\begin{array}{l}
\text { Time } \\
\text { Dummy }
\end{array}\right)_{i, j}+e_{i}
$$

where $i$ indexes the order sequences in the sample and the time dummy variables define the sixteen 15-minute intervals comprising the trading day (interval 1 is 9:00 to 9:15, etc.) and refer to the time of order submission. Table 8 presents estimations of this specification for the three firms. The overall explanatory power of the regressions is not large: the $R^{2} \mathrm{~s}$ are all below ten percent. This suggests that there are significant determinants of liquidity that are not captured. The volume coefficients generally define a positive relation between volume and duration. The time dummies are jointly statistically significant. They suggest that liquidity is lower at the 
beginning of the day. The principal caveat in this regression is the exogeneity assumption. Order submission strategy is endogenous to market conditions. The submitted orders depend on the expected market depth, and our weak correlations may simply reflect a tendency of traders to submit larger orders when the market is more capable of accommodating them.

\section{The Dynamic Behavior of Trades and Quotes.}

This section explores the relations between trades and quotes on the TSE. This behavior is of interest because it provides clues about the information contained in trades, and how this information is incorporated into prices. We employ two approaches. The first involves a vector autoregression model in which trades are characterized solely by their signed volume and the price variable of interest is taken to be the quote midpoint. This analysis is well-suited to investigating the adjustment process of the quote midpoint, and in particular, how the TSE's price limit mechanism affects this adjustment. The second analysis focuses on the behavior of quotes relative to the transaction price, with the purpose of characterizing the information contained in the trades.

\section{Trades and Quotes: a Vector Autoregressive Model.}

Applications of vector autoregressions (VARs) in microstructure analysis are described in Hasbrouck (1991a, 1991b, 1993). A VAR jointly models the dynamic interactions of all variables. The key variables here are the revision in the quote midpoint $\left(r_{t}\right)$ and the signed trade size $\left(x_{t}\right)$. These variables and the associated transformations are summarized in Table 9, and are essentially identical to those employed by Hasbrouck (1991a) for the NYSE data. The most significant departure from the earlier paper involves the time subscript. Here, $t$ refers to minutes and not transactions. The motivation for this change stems from the central role played in the TSE's price limit mechanism by standard wall-clock time.

The trade variables ( $x_{t}$ and its transformations) attempt to reflect the incoming order flow, signed positively for buyer-initiated trades and negatively for seller-initiated trades. We follow the conventional practice of imputing this sign by reference to the prevailing quotes. Because all 
trades except crosses involve the limit order book, the vast majority of the TSE trades can be signed in this fashion.

To capture the state of the market when a price limit is in effect, we construct a signed tradepending variable, pend. This is an indicator variable set to +1 if the pending bid quote at the end of minute $t$ is a warning or special quote. This indicates that a buy order is either walking up the book or is being held to satisfy the continuity requirements. Similarly, pend $d_{t}$ is set to -1 if the pending offer quote at the end of minute $t$ is a warning or special quote.

The VAR for the variable set $z_{t}=\left[\begin{array}{lllll}r_{t} & x_{t}^{0} & x_{t} & x_{t}^{1 / 2} & \text { pend }\end{array}\right]^{\prime}$ was estimated with all variables included through a ten-minute lag using the specification:

$$
z_{t}=A_{0} z_{t}+A_{1} z_{t-1}+\cdots+A_{10} z_{t-10}+u_{t}
$$

where the $A_{t}$ are conformable coefficient matrices and $u_{t}$ is a disturbance vector. The inclusion of the $A_{0} z_{t}$ term on the r.h.s. of (2) reflects a partial recursive structure imposed on the specification: the current quote revision is allowed to depend on the current trade variables. The coefficient estimates are not reported, as it is more illuminating for present purposes to examine the impulse response functions. The impulse response functions characterize the dynamic behavior of the system subsequent to an initial shock (assumed value of $u_{t}$ at time $t=0$ ). Table 10 reports summary estimates of these functions.

For each firm, we study three initial shocks. The first shock corresponds to a buy order with size equal to the 90 th percentile transaction size for the firm (200 shares for Mitsui Construction, 510 shares for Nikon and 50 for JAL). The order-pending variable is set to zero (indicating that the order is fully executed as a single transaction). For all three firms the statistically significant positive implied cumulative price impact of the trade captures the information effect of the trade. Furthermore, for two of the three firms (Nikon and JAL), the initial order leads to significant additional order flow.

Positive autocorrelation in the order flow has been found for the NYSE by Hasbrouck and Ho (1987) and for the Paris Bourse by BHS. As possible economic factors, BHS note the possibilities of: strategic order splitting, imitation (momentum trading) and the sequential arrival 
of orders representing individual trading decisions in response to common information.

Institutional features may also play a role: price discreteness and (at the NYSE) transaction price continuity requirements and fragmentation in the reporting process. The TSE has no reporting fragmentation and neither the TSE nor Paris has continuity requirements. Therefore the positive trade autocorrelation cannot primarily arise from these considerations.

The second initial impulse for each firm is identical to the first, except that the order-pending variable is set "on". This corresponds to an execution that is followed by a special or warning quote, indicating that a portion of the original order is pending. Not surprisingly, this results in a large increase in the total cumulative order flow. For Mitsui Construction, for example, the initial 200 share purchase order gives rise (in expectation) to an additional 91.60 shares. The larger order flow is also associated with a larger quote impact.

It is of some interest to investigate whether the impact of an order on a quote depends on whether it is processed as a single trade or as a sequence that involves warning quotes. The first two impulse response functions are not directly comparable for this purpose because they presumably involve different order sizes. That is, if a trade of 200 shares is followed by a warning quote that indicates more is pending, it must be the case that the original order size was for more than 200 shares. To make the comparison more meaningful, a third impulse response function was computed using an initial impulse corresponding to the total order flow (including that induced) from the second impulse calculation, but with the order-pending variable set to zero. This roughly corresponds to an order of the same total size as in the second impulse calculation, but processed as a single trade. For all three firms, the implied quote impact of this order was smaller than the impact when the order was spread out over multiple executions (second impulse calculation). In all three cases; this difference was statistically significant. It is also worth emphasizing that the lower quote impact in this (third) case is also accompanied by higher cumulative signed order flow.

Special and warning quotes are used when liquidity is relatively low. Liquidity might be low because of random order arrival characteristics. In this case, price limits can time-average the 
arrival of liquidity suppliers and demanders. Alternatively, low liquidity may also signal that incoming orders possess an especially large information content, in which case the price limits merely retard the incorporation of information into the security price. Since warning and special quotes are often hit, they do appear to smooth price movements resulting from transient illiquidity. However, since the cumulative quote impact of an order appears to be higher if the order is handled as a sequence of trades, it appears that the warning and special quotes also impede informationally-based price adjustments.

Two key findings concerning warning and special quotes may be summarized as follows. First, the dynamic analysis suggests that orders for which these quotes are activated have a higher information content. Second, the analysis of outcomes noted that special and warning quotes are often hit by traders who are effectively bettering the prevailing quote, a response which is rational if the order is judged to have a lower information content. These two findings can be reconciled if there is conditioning information available to participants not captured in the present analysis.

One hypothesis involves the size of the order. It was noted in the discussion of the institutional features of the TSE that the display terminal at a member's lead office shows the size of the orders underlying a warning or special quote. Thus, a trader who was part of the offer side of the limit order book and was trying to whether or not to hit a special bid could condition on the size of special bid, subject to the time limits imposed by the saitori. Economic considerations suggest that the special bid would be more likely to be hit if it were for a relatively small quantity. We do not observe the order sizes and so cannot test this mechanism directly. We did, however, examine the total trade volumes of order sequences, classified according to whether or not a special or warning quote was hit. The results did not strongly support the conjecture that sequences with trades at the special-or warning quotes had-relatively small sizes. The exact nature of the conditioning information therefore remains an open question.

\section{Trades and Quotes: The Limit Order Book After a Trade.}

In many markets, it is possible for the quote-setter to condition the bid and offer on the full size of the incoming trade. This is trivially the case when trade size is restricted to a single 
magnitude, but also obtains when a single market-maker quotes a price schedule. Many theoretical models, including Glosten and Milgrom (1985) and Easley and O'Hara (1987) conform to this structure. There are also, on the other hand, many markets in which the quote setter or limit-order trader does not know the full size of the trade that triggers the order. When the quotes derive from a limit order book with many traders, a limit order may be executed in the process of filling an order of much greater size. Rock (1994) and Glosten (1994) model markets of this latter sort.

In these models when competitive quote-setters know the full size of the incoming trade, the equality of marginal revenue and marginal cost holds for each trade size. The marginal revenue associated with a dealer sale, for example, is equal to the marginal cost (the expected terminal value of the security conditional on the trade), and there is no ex post regret. When the quotesetter cannot condition on trade size, however, the equality of marginal cost and revenue holds only in expectation across all trade sizes. The equality between the marginal revenue (the price received for the last share in the dealer sale) and the revised expectation of the security value is broken. In principle, this may lead to revisions in the order book subsequent to a trade that better or worsen the quote. In the Paris CAC system, in particular, BHS find limit order cancellations subsequent to large trades. On the TSE, however, while the quote setter cannot generally condition on the total size of the trade, this may be possible when the trade is represented as a warning or special quote.

To investigate post-trade quote revisions, we define the price-quote continuation after $m$ minutes for a buyer-initiated order sequence as:

$$
C_{m}=\left\{\begin{array}{l}
\left(\begin{array}{l}
\text { Normal offer pending } \\
m \text { minutes after sequence }
\end{array}\right)-\left(\begin{array}{l}
\text { Last transaction price } \\
\text { in sequence }
\end{array}\right), \text { for a purchase } \\
\left(\begin{array}{l}
\text { Last transaction price } \\
\text { in sequence }
\end{array}\right)-\left(\begin{array}{l}
\text { Normal bid pending } \\
m \text { minutes after sequence }
\end{array}\right), \text { for a sale }
\end{array}\right.
$$


Signed in this fashion, $C$ is positive for a purchase if the revised offer is higher than the last transaction price, and negative if there is a quote reversal. The definition is symmetric for a sellerinitiated order sequence. We compute variants of $C$ where the bid and offer quotes employed are those prevailing 1,5 and 10 minutes after the trade.

Table 11 presents means and mean standard errors for the continuations for all order sequences. For each firm, continuations are positive and statistically significantly so. This suggests that quotes deteriorate with the passage of time subsequent to a trade. This is in part due to cancellation of limit orders that establish the best quote. Immediately after a transaction, the stock is automatically requoted. We examined quote revisions that occurred pursuant to these. In 134 instances a quote revision was the first event (ignoring the automatic requoting) after an order sequence that involved a trade. In 106 of these cases the quote deteriorated, presumably as a result of cancellations. That quote deterioration is sometimes observed subsequent to the completion such order sequences, but never in the face of warning quotes issued while the sequence is in progress, suggests that cancellation may be difficult in the latter case. Overall, quote revisions in the absence of intervening trades are relatively infrequent. The continuations in Table 11 are also likely to result from the aforementioned positive autocorrelation in the order flow. A trade in one direction is likely to be followed by another that will cause additional movement in the quote.

We also categorized the quote continuations according to whether or not the transaction or transactions in the sequence took place at a single price. The sequences that are executed at multiple prices are precisely those which stem from orders working through the book. The results here are more ambiguous. Orders filled at a single price exhibit continuations. Those filled at multiple prices tend to exhibit reversals (statistically significant only in the case of JAL). This suggests that liquidity may be restored subsequent to large trades. 


\section{Conclusions.}

This paper investigates the properties of intraday trades and quotes on the Tokyo Stock Exchange (TSE). In comparison with most of the world's other principal equity markets, the TSE is distinctive in the absence of dealers. In addition, the TSE employs price limits and order handling procedures that delay adjustment in quotes and invite liquidity suppliers.

We examine three stocks with average trading volume in the top third of TSE first section issues for the first three months of 1990, a relatively volatile period. For these firms, the supply of public liquidity is good. Ignoring opening delays, hypothetical small buy or sell orders would be prevented from immediately executing (due to the absence of an acceptable opposing quote) less than $5 \%$ of the time that the TSE is nominally open. Under TSE procedures transactions that would otherwise walk through the limit order book at a succession of deteriorating prices are held, and indicative ("special" or "warning") quotes are issued. Roughly a fifth of the time, these indicative quotes are hit by competing providers of liquidity, obtaining some price improvement for the original order.

A dynamic VAR analysis of trades and quote revisions suggests that holding order size constant, an order that is held with an indicative quote has a larger cumulative price impact than one that is immediately executed in full. This suggests that the price limits do not merely smooth transient liquidity effects, but are also associated with changes in the market depth. Finally, after a market order is executed, the quote hit by the market order generally tends to continue to move in the same direction. This is due in part to order autocorrelation and in part to the cancellation of limit orders. This last effect is consistent with the behavior of traders on the Paris CAC system described by BHS and suggests asymmetric information effects within the limit order book. 


\section{Notes}

${ }^{1}$ The prohibition against members acting as dealers is not a formal Exchange rule. Instead, it appears to derive from a members' committee directive that restricts members proprietary trades associated with price changes. This directive has generally been interpreted as prohibiting two-sided market making. In recent years, however, the prohibition has become less effective, as proprietary trading has become more widespread and monitoring has become more difficult.

${ }^{2}$ See Hamao $(1991,1992)$ for details on the distinction between the first and second sections.

${ }^{3}$ Although NYSE Rule 79 requires floor offical approval for large price changes (one dollar if the share price is under twenty dollars and two dollars if over), this circumstance is relatively rare.

${ }^{4}$ Intraday patterns in U.S. data are discussed by Admati and Pfleiderer (1988), Foster and Viswanathan (1990, 1993), Harris (1986, 1989), Jain and Joh (1988), McInish and Wood (1992), Mulherin and Gerety (1989), and Wood, McInish and Ord (1985). Lehmann and Modest (1994) also document intraday patterns in Japanese equity transactions data.

${ }^{\text {s}}$ The delivery and settlement occurs on the third business day after the transaction (" $T+3$ ").

${ }^{6}$ Lehmann and Modest find a number of instances in which an order was permitted to walk through the book with no issuance of warning quotes. Our sample did not contain any such sequences. 


\section{References}

Admati, A. R. and P. Pfleiderer, 1988, "A Theory of Intraday Patterns: Volume and Price Variability," Review of Financial Studies, 1, 3-40.

Amihud, Y. and H. Mendelson, 1989, "Market Microstructure and Price Discovery of the Tokyo Stock Exchange," Japan and the World Economy, 1, 341-370.

Amihud, Y. and H. Mendelson, 1991, "Volatility, Efficiency and Trading: Evidence from the Japanese Stock Market", Journal of Finance, 46, 1765-89.

Amihud Y. and H. Mendelson, 1993, "Liquidity Trading Costs and Asset Prices: Implications for Japan", in I. Walter and T. Hiraki, eds., Restructuring Japan's Financial Markets, Business One Irwin, Homewood, II.

Biais, B., P. Hillion and C. Spatt, 1994, "An Empirical Analysis of the Limit Order Book and the Order Flow in the Paris Bourse," forthcoming, Journal of Finance.

Easley, D. and M. O'Hara, 1987, "Price, Trade Size, and Information in Securities Markets," Journal of Financial Economics, 19, 69-90.

Foster, F. D. and S. Viswanathan, 1990, "A Theory of the Interday Variations in Volumes, Variances and Trading Costs in Securities Markets," Review of Financial Studies, 3, 593-624.

Foster, F. D. and S. Viswanathan, 1993, "Variations in Trading Volume, Return Volatility and Trading Costs: Evidence on Recent Price Formation Models," Journal of Finance, 48, 187-211.

Glosten, L.R., 1994, “Is the Electronic Open Limit Order Book Inevitable?", Journal of Finance, $49,1127-1161$. 
Glosten, L. R. and P. R. Milgrom, 1985, "Bid, Ask and Transaction Prices in a Specialist Market with Heterogeneously Informed Traders," Journal of Financial Economics, 14, 71-100.

Hamao, Y., 1991, "A Standard Data Base for the Analysis of Japanese Security Markets," Journal of Business, 64, 87-102.

Hamao, Y., 1992, "Tokyo Stock Exchange," in The New Palgrave Dictionary of Money and Finance, Macmillan Press, London.

Harris, L. E., 986, “A Transactions Data Study of Weekly and Intradaily Patterns in Stock Returns," Journal of Financial Economics, 16, 99-117.

Harris, L. E., 1989, “A Day-End Transaction Price Anomaly,” Journal of Financial and Quantitative Analysis, 24, 29-45.

Hasbrouck, J., 1988, "Trades, Quotes, Inventories and Information," Journal of Financial Economics, 22, 229-252.

Hasbrouck, J., 1991a, "Measuring the Information Content of Stock Trades," Journal of Finance, 46, 179-207.

Hasbrouck, J., 1991b, "The Summary Informativeness of Stock Trades: An Econometric Analysis," Review of Financial Studies, 4, 571-595.

Hasbrouck, J., 1993, “Assessing the Quality of a Security Market: A New Approach to Transaction Cost Measurement," Review of Financial Studies, 6, 191-212.

Hasbrouck, J., and T. S. Y. Ho, 1987, "Order Arrival, Quote Behavior and the Return Generating Process," Journal of Finance, 42, 1035-1048.

Jain, P. and G. Joh, 1988, "The Dependence Between Hourly Prices and Trading Volume," Journal of Financial and Quantitative Analysis, 23, 269-283. 
Japan Securities Research Institute, 1992, Securities Market in Japan.

Kato, Kiyoshi, 1990, “Weekly Patterns in Japanese Stock Returns”, Management Science, 36, $1031-1043$.

Lehmann, B. N. and D. M. Modest, 1994, "Trading and Liquidity on the Tokyo Stock Exchange: A Bird's Eye View," Journal of Finance, 44, 951-984.

Lindsey, R. R. and U. Schaede, 1992, "Specialist vs Saitori: Market Making in New York and Tokyo," Financial Analysts Journal, 48, 48-57.

McInish, T. H. and R. A. Wood, 1992, "An Analysis of Intraday Patterns in Bid/Ask Spreads for NYSE Stocks," Journal of Finance, 47, 753-764.

Mulherin, J. H. and M. S. Gerety, 1989, "Intraday Trading Behavior in Securities Markets: Hourly NYSE Volume and Returns, 1933-1988," Working Paper, U.S. Securities and Exchange Commission.

Rock, K., 1994, “The Specialist's Order Book and Price Anomalies”, Review of Financial Studies, forthcoming.

Takagi, S., 1993, "The Organization and Microstructure of the Secondary Stock Market in Japan," in S. Takagi (ed.), Japanese Capital Markes, Basil Blackwell, Cambrigde, MA.

Tokyo Stock Exchange, 1993a, Teikan-tou Shokisoku Shu (Constitution and Rules) (in Japanese).

Tokyo Stock Exchange, 1993b, Shokisoku Naiki Shu (Rules and Internal Regulations) (in Japanese).

Tokyo Stock Exchange, 1993c, TSE Fact Book. 
Wood, R. A., T. H. McInish and J. K. Ord, 1985, “An Investigation of Transactions Data for NYSE Stocks," Journal of Finance, 40, 723-739. 
Table 1.

TSE Tick Sizes and Maximum Price Variations (¥ per Share).

\begin{tabular}{lrc}
\hline Share Price & Tick Size & Max Price Variation \\
\cline { 3 - 4 }$<500$ & 1 & 5 \\
$500-1,000$ & 1 & 10 \\
$1,000-1,500$ & 10 & 20 \\
$1,500-2,000$ & 10 & 30 \\
$2,000-3,000$ & 10 & 40 \\
$3,000-5,000$ & 10 & 50 \\
$5,000-10,000$ & 10 & 100 \\
$10,000-30,000$ & 100 & 200 \\
$30,000-50,000$ & 100 & 300 \\
$50,000-100,000$ & 100 & 500 \\
$100,000-500,000$ & 1,000 & 5,000 \\
$500,000-1,000,000$ & 1,000 & 10,000 \\
$1,000,000-1,500,000$ & 10,000 & 20,000 \\
$1,500,000-2,000,000$ & 10,000 & 30,000 \\
$2,000,000-3,000,000$ & 10,000 & 40,000 \\
$3,000,000-5,000,000$ & 10,000 & 50,000 \\
$5,000,000-10,000,000$ & 10,000 & 100,000 \\
$\geq 10,000,000$ & 10,000 & 200,000 \\
\hline & & \\
\hline
\end{tabular}

Notes: The maximum price variation is the largest transaction-to-transaction price change that is permitted to occur unimpeded. Tick size ranges include the upper end of the indicated range. Price variation ranges include the lower end of the indicated range. 
Table 2

Evolution of the Limit Order Book: An Example.

Time 0 . Opening trade at $¥ 1,540$.

Time 1. The Book: Sell Quantity Price (¥) Buy Quantity

$\begin{array}{lll}3,000 & 1,560 & \\ 9,000 & 1,550 & \\ & 1,540 & \\ & 1,530 & 5,000 \\ & 1,520 & 4,000\end{array}$

Quotes: $¥ 1,520$ bid; $¥ 1,550$ offered (regular quotes).

Time 2. Order arrival: 10,000 shares to buy at the market.

Time 3. Transaction: 9,000 shares at $¥ 1,550$

Book:

$\begin{array}{ll}\text { Sell Quantity } & \text { Price } ¥) \\ 3,000 & 1,560 \\ & 1,550 \\ 1,540 \\ 1,530 \\ 1,520 \\ 1,510\end{array}$

Buy Quantity

Time 4. Transaction: 1,000 shares at $¥ 1,560$.

Quotes: $¥ 1,550$ bid (warning); $¥ 1,560$ offered (regular).

\begin{tabular}{|c|c|c|c|}
\hline \multirow[t]{7}{*}{ Book: } & Sell Quantity & Price $(¥)$ & Buy Quantity \\
\hline & 2,000 & 1,560 & \\
\hline & & 1,550 & \\
\hline & & 1,540 & \\
\hline & & 1,530 & \\
\hline & & 1,520 & 5,000 \\
\hline & & 1,510 & 4,000 \\
\hline
\end{tabular}

Time 5. Order arrival: 2,000 shares to sell at market.

Time 6. Quotes: $¥ 1,520$ bid (regular); $¥ 1,550$ offered (warning).

Time 7. Quotes: $¥ 1,520$ bid (regular); $¥ 1,540$ offered (warning).

Time 8. Quotes: $¥ 1,520$ bid (regular); $¥ 1,530$ offered (warning).

Time 9. Order arrival: 2,000 shares to buy at $¥ 1,530$.

Time 10 . Transaction: 2,000 shares at $¥ 1,530$. 
Table 3.

Information Available to Market Participants

Panel A: System-traded issues.

\begin{tabular}{|c|c|c|}
\hline Participant & Location & Information \\
\hline $\begin{array}{l}\text { General } \\
\text { Public }\end{array}$ & $\begin{array}{l}\text { Subscription } \\
\text { display units }\end{array}$ & $\begin{array}{l}\text { Open, high, low and last transaction prices, special quotes, } \\
\text { cumulative volume. No order entry. }\end{array}$ \\
\hline \multirow[t]{3}{*}{ Members } & $\begin{array}{l}\text { Member's } \\
\text { Branch Offices }\end{array}$ & $\begin{array}{l}\text { Open, high, low and last transaction prices, regular, warning, } \\
\text { and special quotes, cumulative volume. No order entry. }\end{array}$ \\
\hline & $\begin{array}{l}\text { Member's Lead } \\
\text { Office }\end{array}$ & $\begin{array}{l}\text { All information available at a branch office plus (on a query } \\
\text { basis with no rebroadcast): all orders in the book (no } \\
\text { identification); of accumulated trading volume by member } \\
\text { firms (with member identification). Automated order entry. }\end{array}$ \\
\hline & $\begin{array}{l}\text { Saitori's } \\
\text { computer } \\
\text { terminal. }\end{array}$ & $\begin{array}{l}\text { Open, high, low, and last transaction prices, cumulative } \\
\text { volume, all orders in the book (no identification). } \\
\text { No order entry. }\end{array}$ \\
\hline
\end{tabular}

Panel B: Floor-traded issues.

\begin{tabular}{|c|c|c|}
\hline Participant & Location & Information \\
\hline $\begin{array}{l}\text { General } \\
\text { Public }\end{array}$ & $\begin{array}{l}\text { Subscription } \\
\text { display units }\end{array}$ & $\begin{array}{l}\text { Open, high, low and last transaction prices, special quotes, } \\
\text { cumulative volume. No order entry. }\end{array}$ \\
\hline \multirow[t]{4}{*}{ Members } & $\begin{array}{l}\text { Member's } \\
\text { Branch Offices }\end{array}$ & $\begin{array}{l}\text { Same as general public. } \\
\text { No order entry. }\end{array}$ \\
\hline & $\begin{array}{l}\text { Member's Lead } \\
\text { Office }\end{array}$ & $\begin{array}{l}\text { Same as general public, } \\
\text { No order entry. }\end{array}$ \\
\hline & $\begin{array}{l}\text { Member booths } \\
\text { on the TSE } \\
\text { floor }\end{array}$ & $\begin{array}{l}\text { All orders in the book (without order identification) and the } \\
\text { list of accumulated trading volume by member firms (with } \\
\text { identification). Orders may be entered prior to the open. } \\
\text { Small orders may be entered from the member booth at any } \\
\text { time. }\end{array}$ \\
\hline & $\begin{array}{l}\text { Saitori post on } \\
\text { the TSE floor }\end{array}$ & $\begin{array}{l}\text { Same as member booths; plus member identification (for large } \\
\text { orders only). All orders not entered from the member booths } \\
\text { are conveyed orally to the saitori. }\end{array}$ \\
\hline
\end{tabular}

Notes: In addition, for both floor- and system-traded issues, the TSE's monitoring facilities have available the full limit order book, with member identification (but not the ultimate customer). 
Table 4.

Summary Statistics.

\begin{tabular}{|c|c|c|c|}
\hline & Mitsui Const. & Nikon & $J A L$ \\
\hline $\begin{array}{l}\text { Average Daily } \\
\text { Closing Price Per } \\
\text { Share (¥) }\end{array}$ & 1,268 & 1,521 & 16,702 \\
\hline $\begin{array}{l}\text { Market Capitalization } \\
(3 / 3190 \text {, Billion } ¥)\end{array}$ & 235 & 531 & 2,422 \\
\hline $\begin{array}{l}\text { Average Number of } \\
\text { Daily Transactions }\end{array}$ & 50.6 & 93.7 & 138.7 \\
\hline $\begin{array}{l}\text { Ranking among all } \\
\text { TSE section } 1 \text { stocks } \\
\text { in average } ¥ \\
\text { transaction volume }\end{array}$ & 413 & 146 & 55 \\
\hline $\begin{array}{l}\text { Median Transaction } \\
\text { Size (100-Share lots) }\end{array}$ & 20 & 30 & 2 \\
\hline Average Spread ( $¥)$ & 12.55 & 12.48 & 109.24 \\
\hline Average Spread (\%) & 1.00 & .83 & .66 \\
\hline
\end{tabular}

Notes: Market statistics are computed using the transaction and quote data from January through March, 1990. 
Table 5.

Times With Impaired Liquidity.

\begin{tabular}{|c|c|c|c|c|c|c|c|}
\hline & & \multicolumn{2}{|c|}{ Mitsui Const. } & \multicolumn{2}{|c|}{ Nikon } & \multicolumn{2}{|c|}{$J A L$} \\
\hline \multicolumn{2}{|c|}{ Side of market with impaired liquidity. } & $N$ & $\%$ & $N$ & $\%$ & $N$ & $\%$ \\
\hline \multirow[t]{5}{*}{ Sales } & Price variation & 17 & 0.5 & 42 & 0.8 & 8 & 0.2 \\
\hline & Order in Progress & 112 & 1.0 & 180 & 0.9 & 182 & 0.8 \\
\hline & Null bid & 1 & 0.0 & 13 & 0.3 & 5 & 0.1 \\
\hline & Opening delay & 113 & 6.0 & 115 & 4.5 & 115 & 1.4 \\
\hline & Total & 243 & 7.5 & 350 & 6.5 & 310 & 2.4 \\
\hline \multirow[t]{5}{*}{ Purchases } & Price variation & 38 & 1.5 & 49 & 1.8 & 21 & .1 \\
\hline & Order in Progress & 88 & 1.1 & 183 & 1.3 & 125 & .6 \\
\hline & Null offer & 12 & 0.7 & 22 & 1.4 & 4 & .0 \\
\hline & Opening delay & 114 & 6.0 & 115 & 2.7 & 115 & 1.4 \\
\hline & Total & 252 & 9.3 & 369 & 7.3 & 265 & 2.1 \\
\hline Both & Total & 122 & 6.3 & 131 & 3.3 & 61 & 1.6 \\
\hline
\end{tabular}

Notes: Liquidity is considered to impaired when a market order cannot be executed immediately by hitting the prevailing opposite quote. Table reports the number of instances and relative duration (total duration as a percentage of the time that the TSE is open). For sales, a price variation impediment means that the bid quote lies outside of the permissible intraday price variation. Order in progress means that a sale is in progress, but has been halted with a warning or special quote. A null bid means that no valid bid is posted. Conditions for purchases are defined analogously. The sample for the three stocks is January through March of 1990. 
Table 6.

\section{Description of Order}

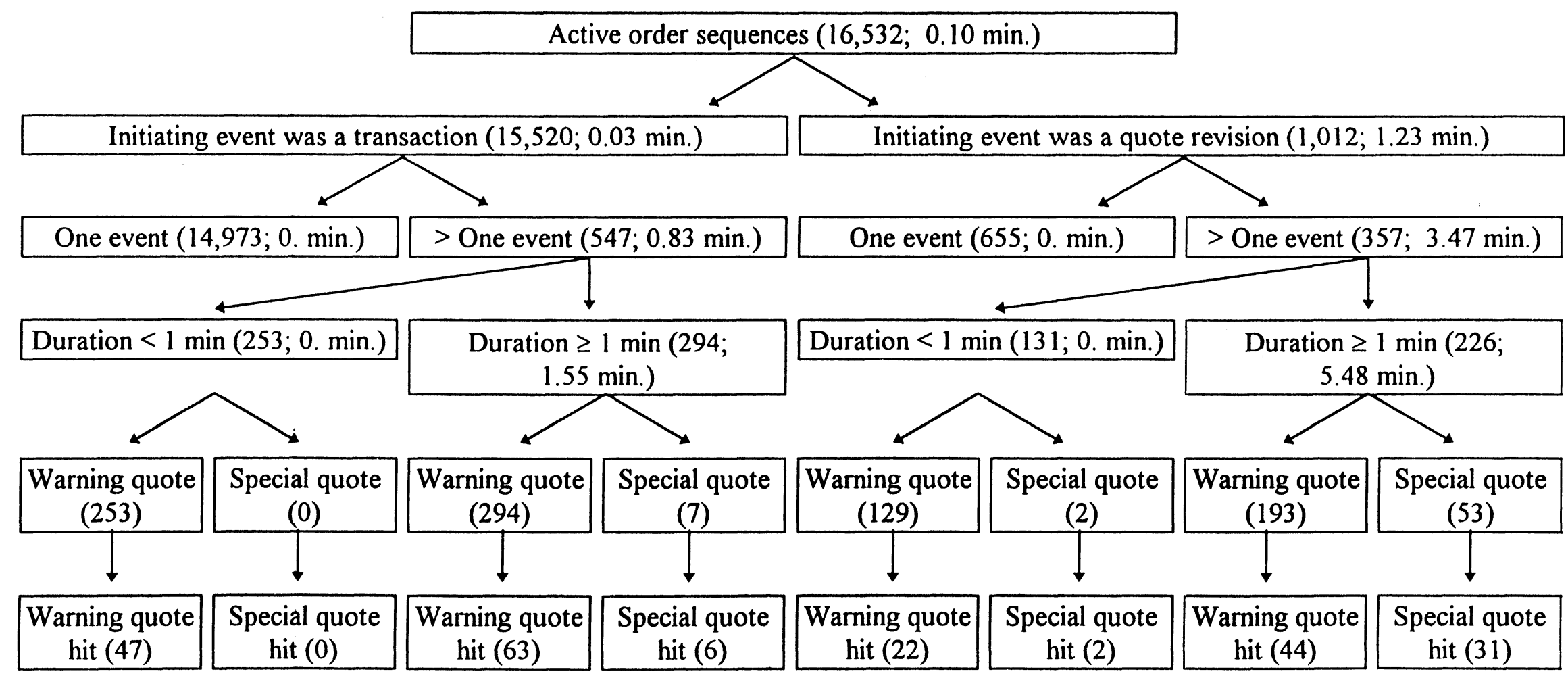


Notes: an order sequence is a consecutive group of trade and quote events that may be inferred to have arisen from one or more orders. The start of an active order sequence in the buy direction is indicated by a transaction above the current bid quote or a quote that improves on the current bid. In the case of a transaction, the sequence immediately terminates if a normal bid quote is immediately posted. Otherwise, if a warning or special bid is posted, the sequence is presumed to continue until a normal bid is posted or the trading session ends. The diagram reports the number and types of these sequences. Sequences that possessed at least one warning quote are classified according to whether a warning quote in the sequence was hit (and similarly for special quotes). Parentheses contain counts (number of such events in the sample) and average sequence durations. The sample for the three stocks is January through March of 1990. 
Table 7.

The Outcomes of Warning and Special Quotes.

\begin{tabular}{|c|c|c|c|c|c|}
\hline \multirow[b]{3}{*}{ Ending event } & & \multicolumn{4}{|c|}{ Starting event } \\
\hline & & \multicolumn{2}{|c|}{ Warning quote } & \multicolumn{2}{|c|}{ Special quote } \\
\hline & & Number & $\begin{array}{c}\text { Mean duration } \\
\text { (min.) }\end{array}$ & Number & $\begin{array}{c}\text { Mean duration } \\
\text { (min.) }\end{array}$ \\
\hline All events & & 1,052 & 0.75 & 77 & 11.31 \\
\hline Regular quote & & 17 & 0.76 & 0 & \\
\hline Warning quote & & 49 & 1.39 & 0 & \\
\hline Special quote & & 26 & 2.31 & 15 & 23.20 \\
\hline Null quote & & 5 & 0.80 & 0 & \\
\hline Trade & $\begin{array}{l}\text { Warning or Special } \\
\text { quote hit }\end{array}$ & 199 & 0.66 & 39 & 6.10 \\
\hline & Not hit & 755 & 0.68 & 21 & 12.00 \\
\hline Session ends & & 1 & 3.00 & 2 & 16.50 \\
\hline
\end{tabular}

Notes: Table describes the transitions from warning and special quote conditions and the mean durations of these transitions. The mean durations are computed from time stamps rounded to the last minute. The sample for the three stocks is January - March of 1990. 
Table 8.

\section{Durations of Transaction Order Sequences}

\begin{tabular}{|c|c|c|c|c|c|c|}
\hline \multirow[b]{2}{*}{ Variable } & \multicolumn{2}{|c|}{ Mitsui Const. } & \multicolumn{2}{|c|}{ Nikon } & \multicolumn{2}{|c|}{$J A L$} \\
\hline & Coeff. & $T$ & Coeff. & $T$ & Coeff. & $T$ \\
\hline Volume & 0.000182 & 2.04 & 0.00144 & 11.68 & 0.00630 & 24.61 \\
\hline Log(Volume) & 0.191 & 7.67 & -0.040 & -1.46 & -0.053 & -9.06 \\
\hline $9: 00-9: 15$ & 0.222 & 1.93 & 0.590 & 4.39 & 0.157 & 6.75 \\
\hline $9: 16-9: 30$ & -0.534 & -4.47 & 0.107 & 0.80 & 0.031 & 1.34 \\
\hline $9: 31-9: 45$ & -0.437 & -3.58 & 0.007 & 0.05 & 0.018 & 0.77 \\
\hline $9: 46-10: 00$ & -0.575 & -4.78 & 0.061 & 0.44 & 0.008 & 0.39 \\
\hline $10: 01-10: 15$ & -0.365 & -2.99 & 0.095 & 0.72 & 0.0136 & 0.60 \\
\hline $10: 16-10: 30$ & -0.503 & -4.07 & 0.082 & 0.59 & 0.008 & 0.35 \\
\hline $10: 31-10: 45$ & -0.537 & -4.30 & 0.092 & 0.63 & 0.017 & 0.72 \\
\hline $10: 46-11: 00$ & -0.535 & -4.03 & 0.077 & 0.51 & 0.022 & 0.85 \\
\hline $13: 00-13: 15$ & -0.435 & -3.14 & 0.522 & 3.30 & -0.003 & -0.10 \\
\hline $13: 16-13: 30$ & -0.426 & -3.08 & 0.084 & 0.53 & 0.005 & 0.20 \\
\hline $13: 31-13: 45$ & -0.537 & -3.94 & 0.051 & 0.33 & 0.020 & 0.78 \\
\hline $13: 46-14: 00$ & -0.388 & -3.06 & 0.045 & 0.30 & 0.012 & 0.46 \\
\hline $14: 01-14: 15$ & -0.504 & -3.88 & 0.119 & 0.82 & 0.013 & 0.48 \\
\hline $14: 16-14: 30$ & -0.483 & -4.00 & 0.068 & 0.49 & 0.009 & 0.35 \\
\hline $14: 31-14: 45$ & -0.565 & -4.83 & 0.041 & 0.29 & 0.024 & 0.99 \\
\hline $14: 46-15: 00$ & -0.533 & -4.57 & 0.108 & 0.80 & 0.068 & 2.95 \\
\hline$R^{2}$ & 0.063 & & 0.055 & & 0.091 & \\
\hline $\begin{array}{l}\operatorname{Pr}(\text { No time } \\
\text { effect) }\end{array}$ & $<.0001$ & & .0019 & & $<.0001$ & \\
\hline
\end{tabular}


Notes: Table reports estimation results for the specification:

$$
\left(\begin{array}{l}
\text { Order S.quence } \\
\text { Duration }
\end{array}\right)_{i}=a\left(\begin{array}{l}
\text { Sequence } \\
\text { Volume }
\end{array}\right)_{i}+b\left(\begin{array}{l}
\text { Log Sequence } \\
\text { Volume }
\end{array}\right)_{i}+\sum_{j=1}^{16} c_{j}\left(\begin{array}{l}
\text { Time } \\
\text { Dummy }
\end{array}\right)_{i, j}+e_{i}
$$

over all order sequences which had a positive transaction volume. Table reports coefficient estimates, the ratio of the coefficient to the standard error, and the right-tail probability for the Ftest of the null hypothesis that all time dummy coefficients are equal. 
Table 9.

Variable Descriptions.

\begin{tabular}{|c|c|}
\hline Variable & Definition \\
\hline$q_{t}^{b}$ & regular bid quote prevailing at end of minute $t$. \\
\hline$q_{t}^{o}$ & regular offer quote prevailing at end of minute $t$. \\
\hline$q_{t}$ & prevailing regular quote midpoint, $\left(q_{t}^{b}+q_{t}^{o}\right) / 2$. \\
\hline$r_{t}$ & quote revision, change in quote midpoint, $q_{t}-q_{t-1}$ \\
\hline pend $_{t}$ & $\begin{array}{l}\text { signed indicator of pending transaction: }+1 \text { if a buy is pending (the bid is } \\
\text { a special or warning quote); }-1 \text { if a sale is pending (the offer is a special } \\
\text { or warning quote). }\end{array}$ \\
\hline$x_{t}$ & $\begin{array}{l}\text { total signed trade volume for minute } t \text {. (Trades are signed as positive if } \\
\text { the transaction price is at the current offer quote, negative if at the } \\
\text { current bid.) }\end{array}$ \\
\hline$x_{t}^{0}$ & $\begin{array}{l}\text { trade indicator variable, } \operatorname{sign}\left(x_{\nu}\right)=+1 \text { if the inferred direction of the } \\
\text { order is a purchase; }-1 \text { if a sale. }\end{array}$ \\
\hline$x_{t}^{1 / 2}$ & signed square-root trade variable, $\operatorname{sign}\left(x_{t}\right) x_{t}^{1 / 2}$ \\
\hline
\end{tabular}

Notes: Table gives the definition of variables used in the vector autoregression analysis. 
Table 10.

Impulse Response Analysis.

\begin{tabular}{|c|c|c|c|c|}
\hline \multirow[b]{2}{*}{ Firm } & \multicolumn{2}{|c|}{ Initial Impulse: } & \multicolumn{2}{|c|}{$\begin{array}{l}\text { Implied behavior } 15 \text { minutes } \\
\text { subsequent to initial impulse }\end{array}$} \\
\hline & $\begin{array}{l}\text { Order size } \\
\text { (shares) }\end{array}$ & More pending? & $\begin{array}{c}\text { Cumulative } \\
\text { signed order flow } \\
\text { (shares) } \\
\end{array}$ & $\begin{array}{c}\text { Cumulative price } \\
\text { change ( } ¥ \text { per } \\
\text { share) }\end{array}$ \\
\hline \multirow[t]{3}{*}{$\begin{array}{l}\text { Mitsui } \\
\text { Construction }\end{array}$} & 200 & No & $\begin{array}{l}188.99 \\
(17.19)\end{array}$ & $\begin{array}{l}3.65 \\
(0.26)\end{array}$ \\
\hline & 200 & Yes & $\begin{array}{l}291.60^{*} \\
(32.56)\end{array}$ & $\begin{array}{c}7.84^{*} \\
(0.58)\end{array}$ \\
\hline & 291.60 & No & $\begin{array}{l}273.20 \\
(21.39)\end{array}$ & $\begin{array}{c}4.09^{*} \\
(0.32)\end{array}$ \\
\hline \multirow[t]{3}{*}{ Nikon } & 510 & No & $\begin{array}{l}816.75 \\
(38.53)\end{array}$ & $\begin{array}{c}4.96 \\
(0.36)\end{array}$ \\
\hline & 510 & Yes & $\begin{array}{l}987.73^{*} \\
(66.27)\end{array}$ & $\begin{array}{l}8.57^{*} \\
(0.54)\end{array}$ \\
\hline & 987.73 & No & $\begin{array}{r}1,435.50^{*} \\
(51.61)\end{array}$ & $\begin{array}{c}6.09^{*} \\
(0.48)\end{array}$ \\
\hline \multirow[t]{3}{*}{$J A L$} & 50 & No & $\begin{array}{l}66.67 \\
(3.36)\end{array}$ & $\begin{array}{l}34.92 \\
(1.44)\end{array}$ \\
\hline & 50 & Yes & $\begin{array}{c}132.50^{*} \\
(7.71)\end{array}$ & $\begin{array}{l}69.71^{*} \\
(6.31)\end{array}$ \\
\hline & 132.50 & No & $\begin{array}{c}150.55^{*} \\
(5.13) \\
\end{array}$ & $\begin{array}{l}48.73^{*} \\
(2.04)\end{array}$ \\
\hline
\end{tabular}

Notes: For each firm, a vector autoregression of the form $z_{t}=A_{0} z_{t}+A_{1} z_{t-1}+\cdots+A_{10} z_{t-10}+u_{t}$ was estimated where $z_{t}=\left[\begin{array}{llllll}r_{t} & x_{t}^{0} & x_{t} & x_{t}^{1 / 2} & \text { pend }]_{t}^{\prime}\end{array}\right]^{\prime}$ and the variables are described in Table 9. This table summarizes the impulse response functions based on these estimations. There are three initial impulses for each firm, differing in initial trade size and whether or not pend is set "on", indicating that part of the order is pending. The two rightmost columns report the implied cumulative trade and price changes. Monte Carlo standard errors are given in parentheses. An asterisk indicates that the quantity in question (cumulative signed trade or price change) is significantly different (at the .001 level) from the corresponding quantity in impulse response computation immediately above. 
Table 11.

Transaction Price/Quote Continuations.

\begin{tabular}{|c|c|c|c|c|}
\hline \multirow[b]{2}{*}{ Sample } & \multirow{2}{*}{$\begin{array}{c}\text { Subsequent time } \\
\text { (minutes) }\end{array}$} & \multicolumn{3}{|c|}{ Mean quote continuation for: } \\
\hline & & Mitsui Const. & Nikon & $J A L$ \\
\hline \multirow[t]{3}{*}{$\begin{array}{l}\text { All order } \\
\text { sequences }\end{array}$} & 1 & $\begin{array}{c}2.31 \\
(0.12)\end{array}$ & $\begin{array}{l}2.08 \\
(0.08)\end{array}$ & $\begin{array}{l}11.19 \\
(0.48)\end{array}$ \\
\hline & 5 & $\begin{array}{c}2.69 \\
(0.15)\end{array}$ & $\begin{array}{c}2.47 \\
(0.11)\end{array}$ & $\begin{array}{l}14.50 \\
(0.66)\end{array}$ \\
\hline & 10 & $\begin{array}{l}2.76 \\
(0.17)\end{array}$ & $\begin{array}{l}3.02 \\
(0.14)\end{array}$ & $\begin{array}{l}17.62 \\
(0.82)\end{array}$ \\
\hline \multirow[t]{3}{*}{$\begin{array}{l}\text { Order sequences } \\
\text { at a single price. }\end{array}$} & 1 & $\begin{array}{c}2.32 \\
(0.12)\end{array}$ & $\begin{array}{c}2.11 \\
(0.08)\end{array}$ & $\begin{array}{l}11.70 \\
(0.48)\end{array}$ \\
\hline & 5 & $\begin{array}{l}2.85 \\
(0.15)\end{array}$ & $\begin{array}{l}2.61 \\
(0.11)\end{array}$ & $\begin{array}{l}15.21 \\
(0.66)\end{array}$ \\
\hline & 10 & $\begin{array}{l}2.95 \\
(0.17)\end{array}$ & $\begin{array}{c}3.14 \\
(0.14)\end{array}$ & $\begin{array}{l}18.57 \\
(0.82)\end{array}$ \\
\hline \multirow[t]{3}{*}{$\begin{array}{l}\text { Sequences with } \\
\text { multiple prices. }\end{array}$} & 1 & $\begin{array}{l}2.12 \\
(0.84)\end{array}$ & $\begin{array}{l}1.30 \\
(0.62)\end{array}$ & $\begin{array}{r}-10.05 \\
(4.47)\end{array}$ \\
\hline & 5 & $\begin{array}{l}-1.23 \\
(0.95)\end{array}$ & $\begin{array}{l}-0.85 \\
(0.68)\end{array}$ & $\begin{array}{r}-14.74 \\
(5.38)\end{array}$ \\
\hline & 10 & $\begin{array}{l}-1.70 \\
(1.03)\end{array}$ & $\begin{array}{c}0.05 \\
(0.79)\end{array}$ & $\begin{array}{r}-21.35 \\
(6.85)\end{array}$ \\
\hline
\end{tabular}

Notes: Table reports average price/quote continuations for all order sequences. A price quote continuation over $m$ minutes is defined as the last transaction price in an order sequence minus the regular bid prevailing $m$ minutes after the last trade if the order sequence is a sale, or (for a sale) the regular offer prevailing $m$ minutes after the last trade minus the last transaction price. Standard errors are given in parentheses. 
Page 40

Figure 1

Daily Closing Prices

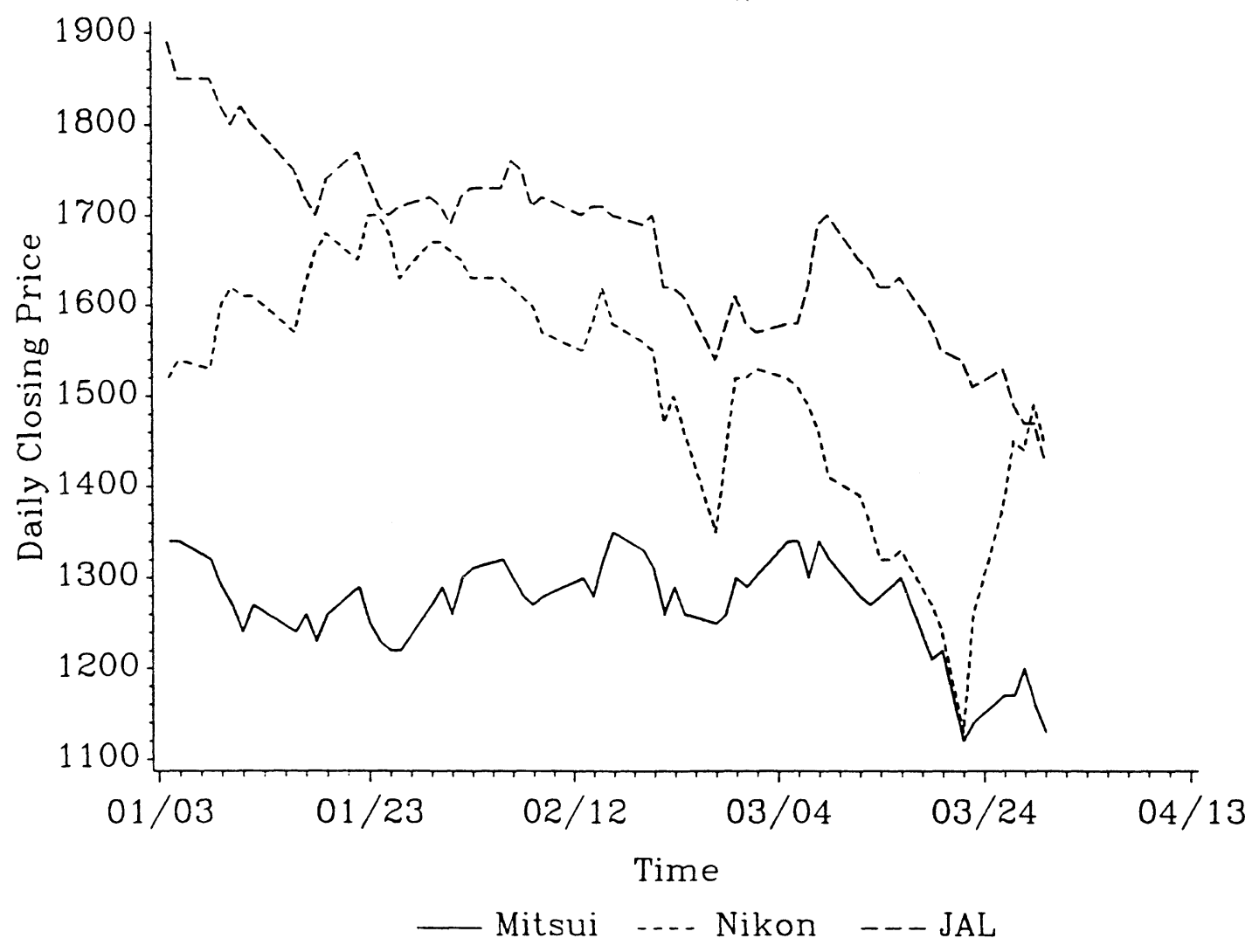

Notes: Figure reports the daily closing prices per share for the three stocks in the sample over the sample period. "Mitsui" refers to Mitsui Construction. The graphed prices for JAL are scaled down by a factor of ten. 
Figure 2

\section{Squared Log Return}

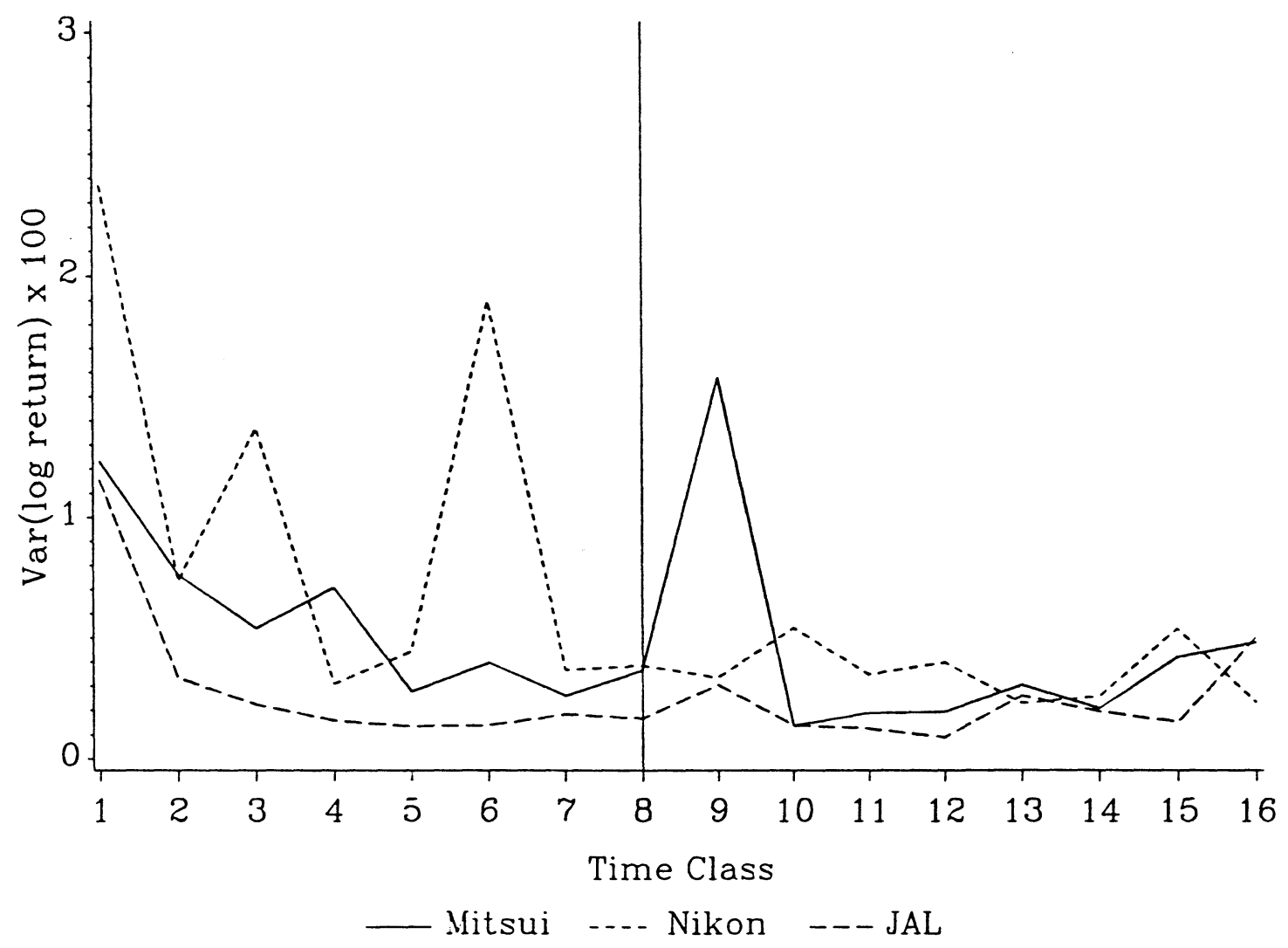

Notes: Figure depicts the average intraday squared log returns for the three firms over the sample. Time classes are generally fifteen minutes long. The return for time class 1 is from the previous day's close to 9:15 AM; time class 2 is from 9:16 to 9:30, etc. The return for time class 9 is from the close of the morning session (11:00) to 1:15 PM. "Mitsui" refers to Mitsui Construction. The sample for the three stocks is January through March of 1990. 
Figure 3.

\section{Average Intraday Spread.}

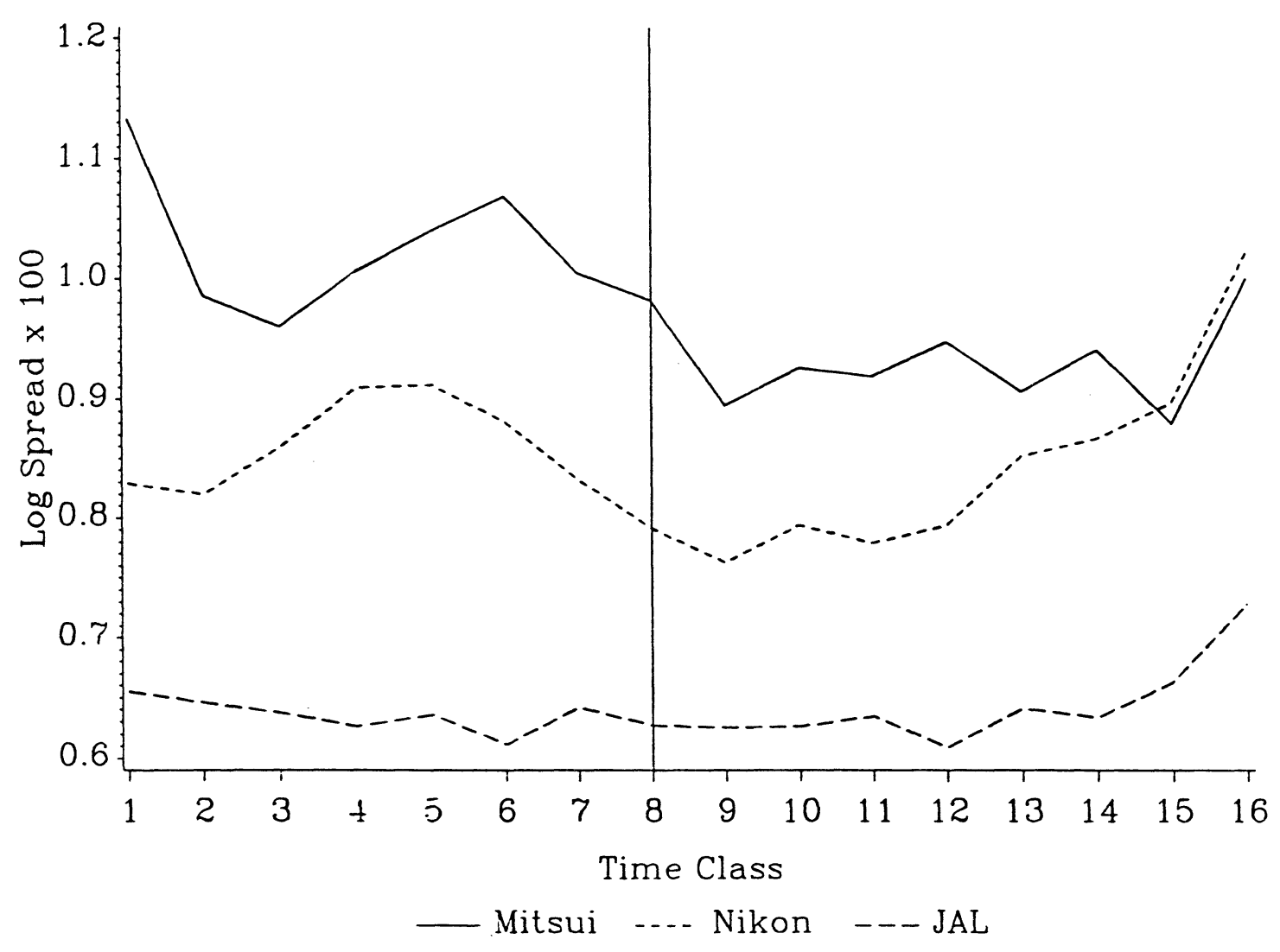

Notes: Figure depicts the average intraday time-weighted spreads for the three firms in the sample. Time classes are fifteen minutes long: time class 1 covers the open to 9:15 AM; time class 2 covers 9:16 to 9:30, etc. Time class 9 covers the open in the afternoon session through 1:15 PM. "Mitsui" refers to Mitsui Construction. The sample for the three stocks is January through March of 1990. 


\section{Figure 4.}

\section{Intraday Trading Volume.}

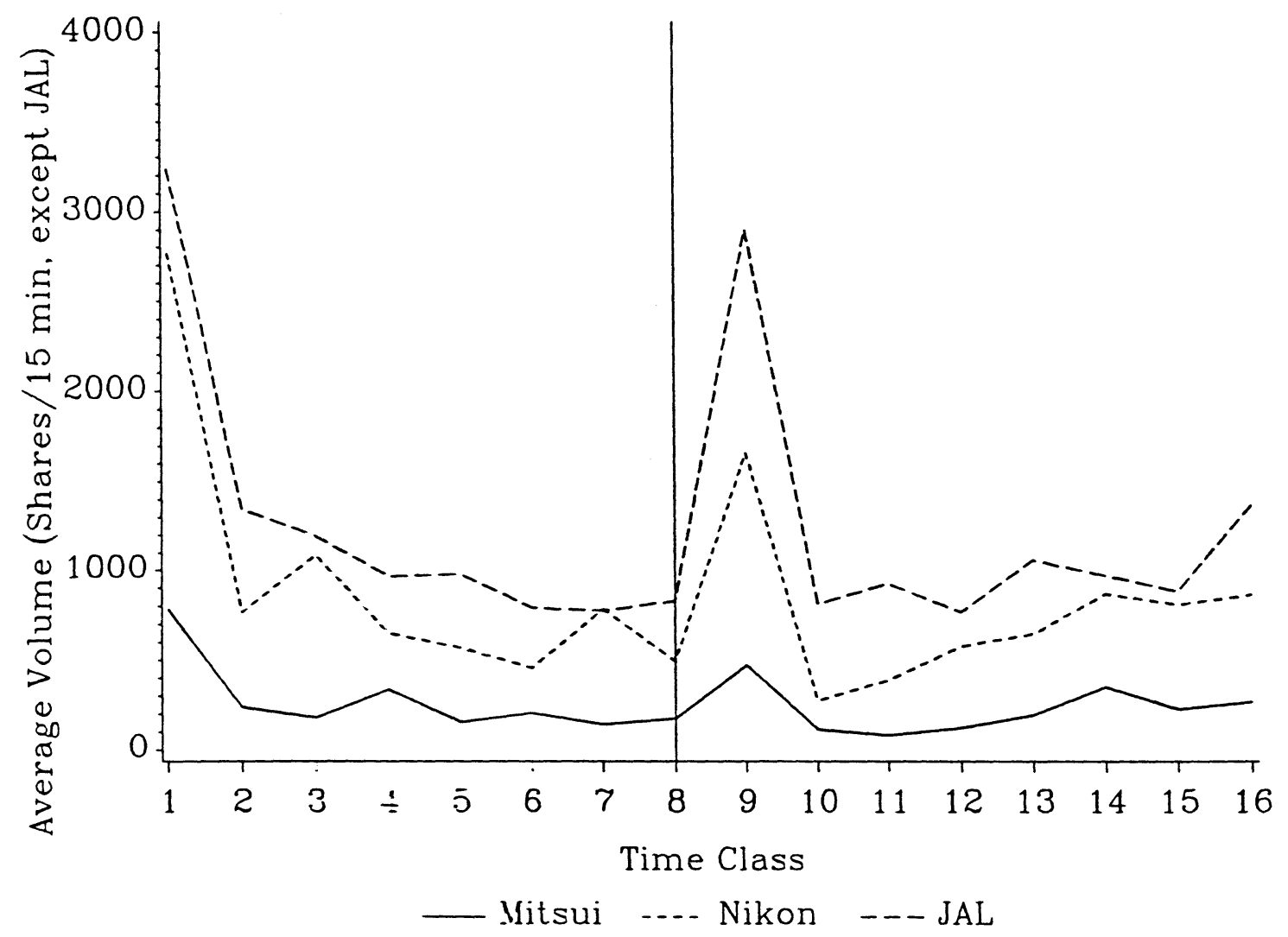

Notes: Figure depicts the average intraday trading volume for the three firms over the sample.

Time classes are fifteen minutes long: time class 1 covers the open to 9:15 AM; time class 2 covers 9:16 to 9:30, etc. Time class 9 covers the open in the afternoon session through 1:15 PM. "Mitsui" refers to Mitsui Construction. The sample for the three stocks is January through March of 1990 . 